\title{
Dexamethasone for the prevention of neonatal respiratory morbidity before elective cesarean section at term
}

\author{
Mohammed N. Salem, ${ }^{1}$ Ahmed M. Abbas, ${ }^{2}$ Mostafa Ashry ${ }^{3}$
}

Keywords: Dexamethasone, respiratory distress, elective cesarean section, neonatal morbidity

\begin{abstract}
Background: Respiratory distress syndrome (RDS) is the principal cause of early neonatal morbidity and mortality.

Objective: The current study aims to evaluate the effect of dexamethasone administration 48 hours before elective cesarean section (CS) at term on neonatal respiratory morbidity.

Methods: The current study was a case-control study conducted between June 2015 and November 2015. Women who attended the labor ward in Sohag University Hospital, Egypt, after 37 weeks of gestation for elective CS were approached for participation. The patients received 2 intramuscular doses of $12 \mathrm{mg}$ dexamethasone 12 hours apart in the 48 hours before CS $(\mathrm{N}=246)$. The control group included women who did not receive dexamethasone before CS during the same period of the study $(N=275)$.
\end{abstract}

Results: No significant differences were detected between the study and control groups with regard to age, parity or gestational age at delivery. There was a significantly higher number of neonates with RDS and transient tachypnea in the control group compared to the study group $(p=0.001)$. The rate of neonatal admission to the neonatal care unit (NICU) was significantly lower in the study group $(p=0.001)$.

Conclusions: Prophylactic dexamethasone administration before elective CS at term significantly reduces neonatal respiratory morbidity and admission to NICU.

${ }^{1}$ Department of Obstetrics and Gynecology, Faculty of Medicine; Sohag University, Sohag, Egypt

${ }^{2}$ Department of Obstetrics and Gynecology, Faculty of Medicine; Assiut University, Assiut, Egypt

${ }^{3}$ Department of Pediatrics, Faculty of Medicine; Sohag University, Sohag, Egypt

\section{Introduction}

Respiratory distress syndrome (RDS) is the principal cause of early neonatal morbidity and mortality and significantly contributes to high costs of neonatal intensive care. ${ }^{1}$

Infants born by elective caesarean section (CS) at term are more likely to develop respiratory morbidity than infants born vaginally. ${ }^{2}$ Elective CS compared with intended vaginal delivery

Please cite this paper as: Salem MN, Abbas AM, Ashry M. Dexamethasone for the prevention of neonatal respiratory morbidity before elective cesarean section at term. Proc Obstet Gynecol. 2016;6(3): Article 2 [ 10 p.]. Available from: http://ir.uiowa.edu/pog/. Free full text article.

Corresponding author: Ahmed M. Abbas, Department of Obstetrics and Gynecology, Faculty of Medicine; Assiut University, Assiut, Egypt, $\underline{\text { bmr90@hotmail.com }}$

Financial Disclosure: The authors report no conflict of interest.

Copyright: (c) 2016 Salem et al. This is an open-access article distributed under the terms of the Creative Commons Attribution License, which permits unrestricted use, distribution, and reproduction in any medium, provided the original author and source are credited. 
Proceedings in Obstetrics and Gynecology, 2016;6(3):2

(VD) leads to a two-fold to four-fold increased risk of overall neonatal respiratory morbidity and even higher relative risks of serious respiratory morbidity in term newborns. ${ }^{3}$ Maternal steroid treatment before preterm delivery is one of the best documented and most cost-effective and life-saving treatments in prenatal medicine. ${ }^{4,5}$

No serious side effects have been reported after administration of corticosteroids during pregnancy, but some studies reported a reduction in fetal body movements, fetal breathing movements and heart rate variation after betamethasone administration. ${ }^{6,7}$

Antenatal corticosteroids for term CS may lead to a reduction in morbidity in babies delivered by CS at term. However, the evidence for the administration of corticosteroids after 37 weeks is still controversial. $^{2}$ Betamethasone given before elective CS at term reduces respiratory distress and admission to pediatric care units. ${ }^{8}$ This is of great importance for developing countries where resources are scarce and it is often difficult to provide expensive treatments such as neonatal care.

Based on high-grade evidence, antenatal corticosteroid therapy is very effective in preventing neonatal respiratory mortality and morbidity, yet remains at low coverage in low/middleincome countries. ${ }^{9}$ The current study aimed to evaluate the effect of prophylactic dexamethasone administration before elective CS at term on neonatal respiratory morbidity.

\section{Patients and methods}

\section{Study setting and design}

The current study was a prospective non-randomized clinical study conducted between June 2015 and November 2015. The study participants were recruited from the labor ward of Sohag University Hospital in Egypt. The institutional ethical review board approved the study.

\section{Study participants}

All pregnant women who presented to the above hospital for elective CS after 37 weeks gestation, based on their reliable dates and confirmed by early ultrasound measurement of crown rump length, were included in the study. Informed written consent was obtained for participation after reading the patient information sheet or having it discussed with patients that were illiterate.

We included in our study pregnant women with a singleton pregnancy, gestational age after 37 weeks, no medical disorders or obstetric complications during the current pregnancy and absence of uterine contractions before the CS.

We excluded women with obstetric complications including preeclampsia, diabetes mellitus (DM), antepartum hemorrhage, known fetal anomaly, twin pregnancy, intrauterine growth restriction and premature ruptured membranes. Also, women who declined to participate in the study were excluded.

All study participants underwent an ultrasound examination before inclusion 
to ensure the date and exclude the presence of multiple gestations, intrauterine growth restriction, oligohydramnios, polyhydramnios and any congenital fetal malformations.

\section{Study intervention}

Dexamethasone administration before elective CS at term is not routinely practiced in the aforementioned hospital. The decision depends on the local protocols of the hospital units working in the daily shifts. So, all eligible participants were allocated to one of the following groups

- Group I (study group): included women who had received two intramuscular doses of $12 \mathrm{mg}$ dexamethasone

(Dexamethasone $8 \mathrm{ml}$, Sigma) 12 hours apart, 48 hours before elective CS.

- Group II (control group): included women who did not receive the scheduled dose taken as a control group.

\section{Follow-up schedule}

All study participants were anaesthetized spinally by a senior resident of anesthesia, and the elective CS was done by a senior resident of obstetrics. All deliveries were attended by a neonatology specialist; details of the resuscitation at the operative theatre were recorded. Apgar scores at 1 and 5 minutes were recorded. All neonates were assessed for signs of RDS [defined as the presence of at least 2 of the following criteria: tachypnea, central cyanosis in room air, expiratory grunting and subcostal, intercostal or jugular retraction and nasal flaring $]^{10}$ or transient tachypnea of newborn (TTN) [defined as a period of rapid breathing higher than the normal range of 40-60 times per minute]. ${ }^{11}$ All neonates admitted to NICU were subjected to chest X-ray for exclusion of other associated pathologies and confirmation of diagnosis of RDS. All data about the need for admission to neonatal intensive care unit (NICU) or the need for mechanical ventilation within 24 hours after birth were recorded.

\section{Study outcomes}

The primary outcome of this study was the incidence of neonatal RDS. The secondary outcomes included the incidence of TTN, incidence of admission to NICU and lastly the need for mechanical ventilation within 24 hours after birth.

\section{$\underline{\text { Statistical analysis }}$}

The data were collected and analyzed using the Statistical Package for Social Science (IBM, SPSS Inc., Chicago, version 21). The demographic data were compared between groups. A Student T-test was used to compare the continuous outcome measures. For dichotomous variables, chi-square was used to estimate the significance value. For analysis, $\mathrm{P}<0.05$ was considered to be significant.

\section{Results}

Out of 591 pregnant women scheduled for elective CS during the study period, 521 of them were enrolled in the study. The causes of exclusion as well as the 
study flowchart are shown in Figure 1.

\section{1women evaluated for participation in the study}

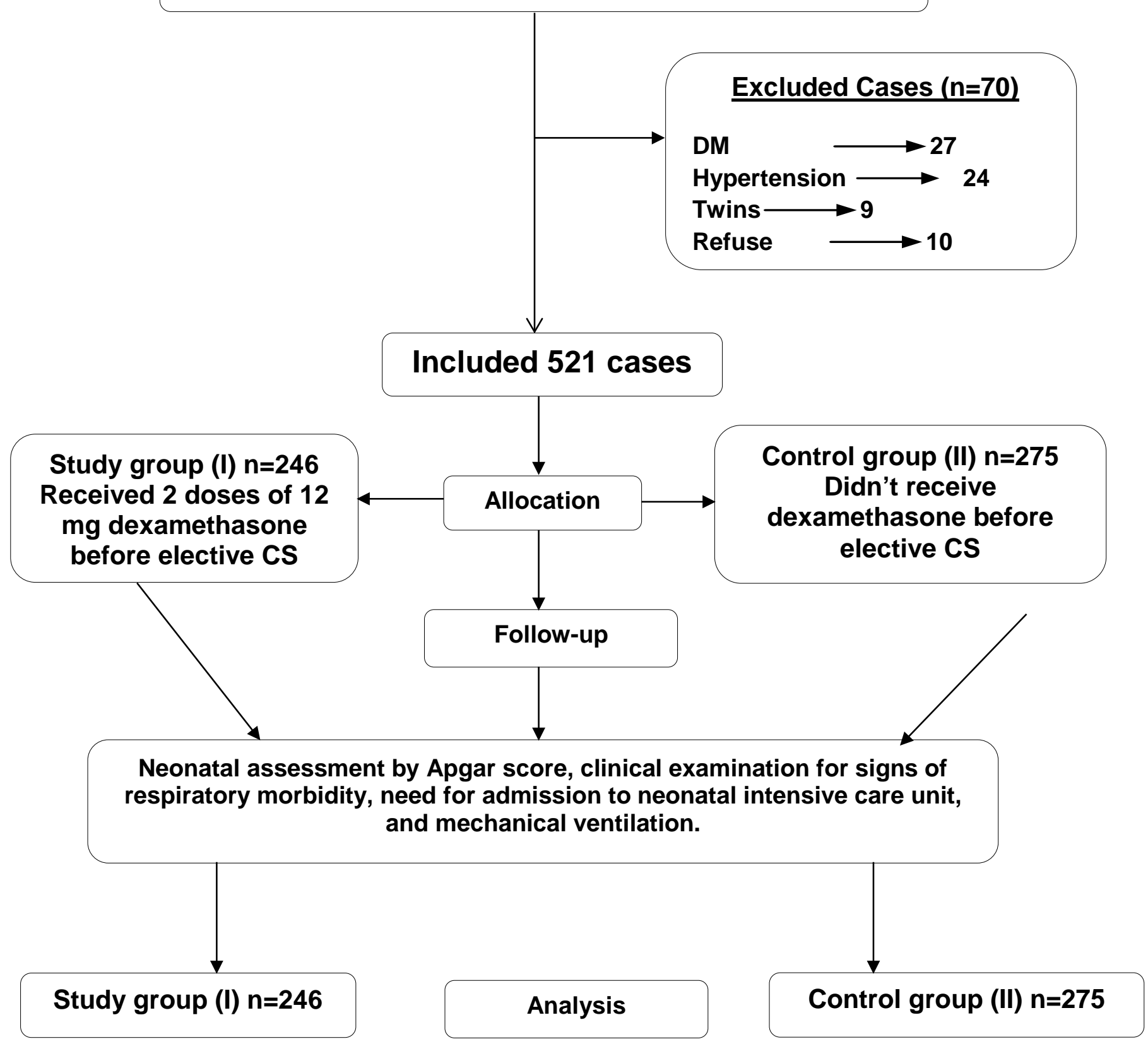

Figure 1: The study flowchart

There were no significant differences between the two groups regarding their age, parity, number of previous miscarriages, gestational age at delivery and body mass index at the time of enrollment (Table

1). 
Table 1: The demographic characteristics of the study participants

\begin{tabular}{|c|c|c|c|}
\hline Variables & $\begin{array}{c}\text { Group I } \\
\text { (study group) } \\
\text { n=246 }\end{array}$ & $\begin{array}{c}\text { Group II } \\
\text { (control group) } \\
\mathbf{n}=275\end{array}$ & p-value \\
\hline Age (years),mean $\pm S D$ & $28.45 \pm 6.17$ & $29.86 \pm 5.9$ & 0.225 \\
\hline Parity, mean $\pm S D$ & $2.47 \pm 1.61$ & $2.15 \pm 1.79$ & 0.092 \\
\hline Previous miscarriages, median (range) & $1(0-4)$ & $2(0-4)$ & 0.329 \\
\hline BMI $\left(\mathrm{Kg} / \mathrm{m}^{2}\right), \operatorname{mean} \pm S D$ & $24.2 \pm 4.6$ & $25.3 \pm 4.3$ & 0.42 \\
\hline Gestational age at delivery (weeks), mean $\pm S D$ & $38.7 \pm 1.58$ & $38.55 \pm 1.63$ & 0.164 \\
\hline Indications of CS, $n(\%)$ & & & 0.866 \\
\hline Repeat CS & $142(57.7 \%)$ & $161(58.5 \%)$ & \\
\hline CS on request & $54(22 \%)$ & $68(24.7 \%)$ & \\
\hline Breech presentation & $21(8.5 \%)$ & $24(8.7 \%)$ & \\
\hline Cephalopelvic disproportion & $15(6.1 \%)$ & $13(4.7 \%)$ & \\
\hline Others & $14(5.7 \%)$ & $9(3.3 \%)$ & \\
\hline
\end{tabular}

BMI; body mass index, CS; cesarean section, SD; standard deviation

There were no significant differences between the two groups with regard to neonatal birth weight and gender. There were significantly higher Apgar scores at
1 and 5 minutes after delivery in the study group (Group I) ( $\mathrm{p}=0.0001$ and 0.011 respectively) (Table 2 ).

\section{Table 2: The neonatal outcome of the two study groups}

\begin{tabular}{|c|c|c|c|}
\hline Variables & $\begin{array}{c}\text { Group I } \\
\text { (study group) } \\
\text { n=246 }\end{array}$ & $\begin{array}{c}\text { Group II } \\
\text { (control group) } \\
\mathbf{n}=\mathbf{2 7 5}\end{array}$ & p-value \\
\hline \multicolumn{4}{|l|}{ Neonatal gender, $n$ (\%) } \\
\hline Male & 139 (56.5\%) & $143(52 \%)$ & \multirow[t]{2}{*}{0.19} \\
\hline Female & $107(43.5 \%)$ & $132(48 \%)$ & \\
\hline Birth weight, mean $\pm S D$ (range) & $\begin{array}{c}3035.6 \pm 231.17 \\
(2560-3750)\end{array}$ & $\begin{array}{c}3095.74 \pm 249.2 \\
(2670-3820)\end{array}$ & 0.832 \\
\hline \multicolumn{4}{|l|}{ Apgar score, mean $\pm S D$} \\
\hline At 1 minute & $8.63 \pm 1.4$ & $6.95 \pm 2.24$ & 0.0001 \\
\hline At 5 minutes & $9.62 \pm 0.33$ & $8.37 \pm 1.19$ & 0.011 \\
\hline \multicolumn{4}{|c|}{ Neonatal respiratory morbidity, $n(\%)$} \\
\hline RDS & $2(0.8 \%)$ & $13(4.7 \%)$ & 0.001 \\
\hline TTN & $5(2 \%)$ & $41(14.9 \%)$ & 0.001 \\
\hline Admission to NICU, $n$ (\%) & $7(2.8 \%)$ & $35(12.7 \%)$ & 0.003 \\
\hline Mechanical ventilation, $\boldsymbol{n}(\%)$ & $2(0.8 \%)$ & $10(3.6 \%)$ & 0.027 \\
\hline CPAP, $n$ (\%) & $5(2 \%)$ & $25(9.1 \%)$ & 0.0001 \\
\hline Nasal oxygen, $n(\%)$ & 0 & 19 (6.9\%) & ------ \\
\hline
\end{tabular}

RDS; respiratory distress syndrome, TTN; transient tachypnea of newborn, NICU; neonatal intensive care unit, CPAP; continuous positive airway pressure ventilation, SD; standard deviation 
Regarding the primary outcome of the study, the incidence of RDS was significantly higher in the control group compared to the study group $(4.7 \%$ versus $0.8 \%$, respectively; $p=0.001$ ). Also, the incidence of TTN was significantly higher in the control group compared to the study group (14.9\% versus $2 \%$, respectively; $p=0.001$ ).

Indications for NICU admission were RDS and some cases of TTN. All cases (15 neonates) of RDS were admitted to $\mathrm{NICU}$, of whom 12 required mechanical ventilator, and 3 responded to continuous positive airway pressure ventilation (CPAP). On the contrary, only cases with severe TTN were admitted to NICU (27 cases) and the rest of them responded to only oxygen therapy on the resuscitator. No cases required mechanical ventilation.

The number of neonates admitted to NICU was significantly higher in the control group than the study group $(p=0.003)$. The same was observed in the number of neonates who needed mechanical ventilation or CPAP in the first 24 hours after birth due to respiratory complications $(p=0.027$, 0.0001 , respectively) (Table 2 ).

\section{Discussion}

The current study evaluated the effect of the use of prophylactic dexamethasone before elective CS at term on neonatal respiratory morbidity. The results show significant improvement in neonatal respiratory condition after administration of dexamethasone with less frequent admission to NICU and use of mechanical ventilation.

As a result of the rapid rise in the rate of CS, especially in developing countries such as Egypt in the last years, there is a critical need for studying the complications of CS, especially those associated with neonatal respiratory morbidity. When infants are delivered at term especially by elective CS before the onset of labor pains, they are usually deprived of necessary hormonal changes, resulting in the development of respiratory complications especially neonatal RDS. ${ }^{12}$

CS is a well-known risk factor for neonatal respiratory morbidity, mostly TTN and RDS in infants near term. ${ }^{13,14}$ But, other confounding factors may contribute to the development of neonatal respiratory morbidities after CS such as the type of anesthesia, neonatal gender, weight, and antenatal maternal medical disorders. ${ }^{15}$ In our study, we excluded women with medical disorders, and all elective cesarean sections were done under spinal anesthesia. Besides that, there were no significant differences between both groups with regard to neonatal weight or gender.

Several mechanisms have been postulated for how the use of antenatal corticosteroids at term prevents neonatal respiratory morbidities. They may act by promoting the molecular mechanisms that allow alveolar fluid drainage. This might be a predominantly lung epithelial sodium channels mechanism. They may also increase the responsiveness to catecholamines and thyroid hormones. ${ }^{16}$ 
A Cochrane systemic review (2009) on the prophylactic administration of corticosteroids before elective CS at term concluded that there was no significant difference between women who received betamethasone as compared to those did not with regard to the incidence of RDS, TTN and the need for mechanical ventilation. There was a significant decrease in the incidence of neonatal admission to NICU (RR=0.15). The study concluded the great need of more studies to further clarify this issue. ${ }^{2}$

In 2014, a randomized controlled study by Nabhan and colleagues in Egypt of 123 women showed that prophylactic administration of 4 doses of $12 \mathrm{mg}$ dexamethasone 48 hours before elective CS performed at gestational age between 34-37 weeks was not superior to noprophylaxis. ${ }^{17}$ There was no significant difference in the incidence of RDS ( $p=0.699), \quad$ TTN $(p=0.612)$, admission to NICU $(p=0.535)$ or the need for mechanical ventilation $(p=509)$. These results are in contrast to our results; it should be noted that the dose of dexamethasone used was different and the gestational age at elective CS was earlier than our study. The difference in the dexamethasone dose and the gestational age of the study participants, as well as the larger sample size in the current study, may be behind the differences in our results.

In 2011, a study was conducted in Brazil by Porto et al. on 273 women. They reported in a randomized triple-blind, placebo-controlled study that betamethasone given at the daily dose of $12 \mathrm{mg}$ for 2 days did not reduce the incidence of respiratory disorders in newborn infants. ${ }^{18}$ Again, their results were different from our study, though it is of note that this study had a different methodology than ours. Specifically, Porto et al. included all deliveries between 34-36 weeks whether born vaginally or by CS; additionally, a different type of corticosteroid was used.

On the contrary, an earlier study in 1995 by Morrison et al. ${ }^{19}$ reported that the incidence of respiratory morbidity was significantly higher in women delivered by elective CS (35.5/1000) compared with CS during labor (12.2/1000) (OR=2.9; 95\% $\quad \mathrm{Cl}=1.9-4.4 ; \quad \mathrm{P}<0.001)$. They found that prophylactic use of betamethasone in that group of women before elective CS at term reduces the risk of respiratory morbidity.

In 2015, a large RCT was conducted in Egypt by Nada et al. to determine whether prophylactic dexamethasone in a dose of $8 \mathrm{mg} / 12$ hours for 3 doses over 48 hours before elective CS at term would decrease the neonatal respiratory morbidity. ${ }^{20}$ They found that the NICU admission rate was significantly lower in the dexamethasone group compared with the control group (3.1\% versus $6.7 \%$, respectively; $p=0.003$ ). These results are in accord with the current study as the rate of NICU admission was $2.8 \%$ in the dexamethasone and $12.7 \%$ in control groups $(p=0.003)$. The rate of TTN was significantly lower in the dexamethasone group compared with the control group $(1.3 \%$ versus $3.4 \%$, respectively; $\quad p=0.014) .{ }^{20}$ Our study agreed with their results as the rate of TTN was $2 \%$ versus $14.9 \%$ in the dexamethasone versus control groups, respectively $(p=0.001)$. However, in contrast to the present study, 
prophylactic dexamethasone did not significantly reduce the incidence of RDS or the need for mechanical ventilation in the Nada et al. study $\left(p=0.103,0.127\right.$ respectively). ${ }^{20}$

Keeping with our results, a recent study in 2016 by Gyamfi-Bannerman and colleagues confirmed that administration of betamethasone to women at 34-36 weeks gestation significantly reduced the rate of TTN and surfactant use. ${ }^{21}$

The main strength of the current study was the use of dexamethasone which is inexpensive, has no major side effects or complications, and has proven benefits. The large sample size of included women in the current study is another merit.

The main limitation of our study was its design as a non-randomized study, not a randomized controlled trial (RCT). Also, we did not compare the neonatal outcome at different gestational ages after 37 weeks to determine the most beneficial time for dexamethasone administration. Further studies are needed to confirm our results and to compare the effects of dexamethasone at different gestational ages after 37 weeks.

In conclusion, prophylactic dexamethasone administration 48 hours before elective CS at term after 37 weeks reduces the rates of neonatal respiratory morbidity as well as the incidence of NICU admission.

\section{References}

1. Miracle X, Di Renzo GC, Stark A, Fanaroff A, Carbonell-Estrany $X$, Saling $E$; Coordinators Of World Association of Perinatal Medicine Prematurity Working Group. Guideline for the use of antenatal corticosteroids for fetal maturation. J Perinat Med. 2008;36(3):191-6.

http://dx.doi.org/10.1515/JPM.2008.032

PubMed PMID: 18576926.

2. Sotiriadis A, Makrydimas G, Papatheodorou S, loannidis JP. Corticosteroids for preventing neonatal respiratory morbidity after elective caesarean section at term. Cochrane Database Syst Rev. 2009 Oct 7;(4):CD006614.

http://dx.doi.org/10.1002/14651858.CD0 06614.pub2 PubMed PMID: 19821379.

3. Hansen AK, Wisborg $\mathrm{K}$, Uldbjerg $\mathrm{N}$, Henriksen TB. Elective caesarean section and respiratory morbidity in the term and near-term neonate. Acta Obstet Gynecol Scand. 2007;86(4):38994.

http://dx.doi.org/10.1080/000163406011 59256 PubMed PMID: 17486457.

4. Roberts D, Dalziel S. Antenatal corticosteroids for accelerating fetal lung maturation for women at risk of preterm birth. Cochrane Database Syst Rev. 2006 Jul 19;(3):CD004454 http://dx.doi.org/10.1002/14651858.cd00 4454.pub2 PubMed PMID: 16856047.

5. Marciniak B, Patro-Małysza J, Poniedziałek-Czajkowska E, KimberTrojnar Z, Leszczyńska-Gorzelak B, Oleszczuk J. Glucocorticoids in pregnancy. Curr Pharm Biotechnol. 2011 May;12(5):750-7. http://dx.doi.org/10.2174/138920111795 470868 PubMed PMID: 21342122. 
6. Mulder EJ, Derks JB, Zonneveld MF, Bruinse HW, Visser GH. Transient reduction in fetal activity and heart rate variation after maternal betamethasone administration. Early Hum Dev. 1994 Jan;36(1):49-60. http://dx.doi.org/10.1016/03783782(94)90032-9 PubMed PMID: 8026364.

7. Derks JB, Mulder EJ, Visser GH. The effects of maternal betamethasone administration on the fetus. $\mathrm{Br} \mathrm{J}$ Obstet Gynaecol. 1995 Jan;102(1):40-6. http://dx.doi.org/10.1111/i.14710528.1995.tb09024.x PubMed PMID: 7833309 .

8. Stutchfield $\mathrm{P}$, Whitaker $\mathrm{R}$, Russell I; Antenatal Steroids for Term Elective Caesarean Section (ASTECS) Research Team. Antenatal betamethasone and incidence of neonatal respiratory distress after elective caesarean section: pragmatic randomised trial. BMJ. 2005 Sep 24;331(7518):662. Epub 2005 Aug 22. http://dx.doi.org/10.1136/bmj.38547.416 493.06 PubMed PMID: 16115831.

9. Mwansa-Kambafwile J, Cousens S, Hansen T, Lawn JE. Antenatal steroids in preterm labour for the prevention of neonatal deaths due to complications of preterm birth. Int J Epidemiol. 2010 Apr;39Suppl 1:i122-33. http://dx.doi.org/10.1093/ije/dyq029

PubMed PMID: 20348115.

10. Edwards MO, Kotecha SJ, Kotecha S. Respiratory distress of the term newborn infant. Paediatr Respir Rev. 2013 Mar;14(1):29-36; quiz 36-7. http://dx.doi.org/10.1016/j.prrv.2012.02. 002Epub 2012 Mar 2. PubMed PMID: 23347658.

11. Warren JB, Anderson JM. Newborn respiratory disorders. Pediatr Rev. 2010 Dec;31(12):487-95; quiz 496. http://dx.doi.org/10.1542/pir.31-12-487 PubMed PMID: 21123510.
12. Jain L, Eaton DC. Physiology of fetal lung fluid clearance and the effect of labor. Semin Perinatol. 2006 Feb;30(1):34-43. http://dx.doi.org/10.1053/j.semperi.2006. 01.006 PubMed PMID: 16549212.

13. Levine EM, Ghai V, Barton JJ, Strom CM. Mode of delivery and risk of respiratory diseases in newborns. Obstet Gynecol. 2001 Mar;97(3):439-42. http://dx.doi.org/10.1016/S00297844(00)01150-9 PubMed PMID: 11239653.

14. Gerten KA, Coonrod DV, Bay RC, Chambliss LR. Cesarean delivery and respiratory distress syndrome: does labor make a difference? Am J Obstet Gynecol. 2005 Sep;193(3 Pt 2):1061-4. http://dx.doi.org/10.1016/j.ajog.2005.05. 038 PubMed PMID: 16157112.

15. van den Berg $A$, van Elburg $R M$, van Geijn HP, Fetter WP. Neonatal respiratory morbidity following elective caesarean section in term infants. A 5year retrospective study and a review of the literature. Eur J Obstet Gynecol Reprod Biol. 2001 Sep;98(1):9-13. http://dx.doi.org/10.1016/S03012115(01)00292-5 PubMed PMID: 11516792.

16. Jain L, Dudell GG. Respiratory transition in infants delivered by cesarean section. Semin Perinatol. 2006 Oct;30(5):296304.

http://dx.doi.org/10.1053/i.semperi.2006. 07.011 PubMed PMID: 17011402.

17. Nabhan A, Al-Helaly A, Ramadan A. Prophylactic antenatal corticosteroid before elective cesarean delivery at or near term to improve perinatal outcome. Med J Cairo Univ. 2014 Mar;82(1):25-8. 
18. Porto AM, Coutinho IC, Correia JB, Amorim MM. Effectiveness of antenatal corticosteroids in reducing respiratory disorders in late preterm infants: randomised clinical trial. BMJ. $2011 \mathrm{Apr}$ 12;342:d1696.

http://dx.doi.org/10.1136/bmj.d1696

PubMed PMID: 21487057.

19. Morrison JJ, Rennie JM, Milton PJ. Neonatal respiratory morbidity and mode of delivery at term: influence of timing of elective caesarean section. $\mathrm{Br}$ J Obstet Gynaecol. 1995 Feb;102(2):101-6. http://dx.doi.org/10.1111/i.14710528.1995.tb09060.x PubMed PMID: 7756199 .

20. Nada AM, Shafeek MM, El Maraghy MA, Nageeb AH, Salah El Din AS, Awad $\mathrm{MH}$. Antenatal corticosteroid administration before elective caesarean section at term to prevent neonatal respiratory morbidity: a randomized controlled trial. Eur J Obstet Gynecol Reprod Biol. 2016 Apr;199:88-91. http://dx.doi.org/10.1016/j.ejogrb.2016.0 1.026Epub 2016 Feb 8. PubMed PMID: 26905469.

21. Gyamfi-Bannerman C, Thom EA, Blackwell SC, Tita AT, Reddy UM, Saade GR, Rouse DJ, McKenna DS, Clark EA, Thorp JM Jr, Chien EK, Peaceman AM, Gibbs RS, Swamy GK, Norton ME, Casey BM, Caritis SN, Tolosa JE, Sorokin Y, Van Dorsten JP, Jain L; NICHD Maternal-Fetal Medicine Units Network. Antenatal Betamethasone for Women at Risk for Late Preterm Delivery. N Engl J Med. $2016 \quad$ Apr 7;374(14):1311-20. http://dx.doi.org/10.1056/NEJMoa15167 83Epub 2016 Feb 4. PubMed PMID: 2684267 